\title{
O INVERSO DA ANÁLISE DA CULPA: LEITURA DA TEORIA DO RISCO A PARTIR DO ROMPIMENTO DE BARRAGEM EM MARIANA/MG
}

\author{
Amanda Cambuí Pereira \\ Universidade Federal da Bahia (UFBA), Bahia. \\ amandacambuip@gmail.com \\ Tagore Trajano de Almeida Silva \\ Universidade Federal da Bahia (UFBA), Bahia. \\ tagoretrajano@gmail.com
}

\begin{abstract}
RESUMO: O presente trabalho estuda a evolução da responsabilidade civil, calcada como contemporânea, e seus reflexos na teoria do risco integral, tendo como ponto de partida as legislações e princípios gerais do direito que desembocaram numa compreensão jurisprudencial moderna através de um estudo de caso. Na nova face da responsabilidade civil, optou-se, enquanto fios condutores, pelo estudo das obras de Alvino Lima, Nelson Rosenvald e Geneviève Viney. Nesse ínterim, o objetivo deste estudo foi o de verificar a possibilidade de delimitar a teoria do risco integral a partir da compreensão contemporânea do "direito de danos", conforme expressão emplacada por Nelson Rosenvald, levantando a hipótese de que a função preventiva do Direito por ser pouco utilizada, não colabora para abrandar os riscos ambientais já existentes, que podem se concretizar em danos. A pesquisa, orientada pelo método dedutivo, mediante análise bibliográfica-documental, indicou que esta teoria possui bases antigas e consolidadas pela jurisprudência atual, mas padece de robustez técnica em determinados aspectos. Todavia, o arcabouço jurídicoteórico conferido pelos entendimentos atuais da responsabilidade civil pode ser viabilizado por meio da teoria do risco integral, aplicável, especialmente, aos danos praticados em face do meio ambiente.
\end{abstract}

PALAVRAS-CHAVE: Responsabilidade civil contemporânea. Teoria do risco integral. Rompimento de barragem.

The inverse of the fault analysis: reading about the theory of risk from the dam failure at Mariana/MG

\begin{abstract}
The thesis studies the evolution of civil responsibility, called as contemporary, and its reflexes in theory of integral risk, starting with the corresponding legislations and corresponding general principles of law that have created a modern vision of the jurisprudence through a case study. In the new face of civil responsibility, it was decided to study the works written by Alvino Lima, Nelson Rosenvald and Geneviève Viney. In the meantime, the goal of this study was to verify the possibility of delimiting the theory of integral risk from the contemporary understanding of the civil responsibility, raising the hypothesis that the preventive function of the law, as it is not much used, doesn't help to mitigate the existing environmental risks, which can be materialized in damages. The research, guided by the deductive method, through bibliographic-documentary analysis, indicated that this theory has old bases and it was consolidated by the current jurisprudence, but suffers from technical consistency in certain aspects. However, the legal bases provided by the current understandings of civil responsibility can be made via the theory of integral risk, applicable, especially, to the damages practiced against the environment.
\end{abstract}


O inverso da análise da culpa: leitura da teoria do risco a partir do rompimento de barragem em Mariana/MG

KEYWORDS: Civil liability. Theory of integral risk. Dam failure.

\section{INTRODUÇÃ̃O}

O presente estudo foi realizado atento às modificações relacionadas à culpa, com base na célebre obra "Da culpa ao risco", publicada em 1938, de Alvino Ferreira Lima. Averiguou-se a supressão do elemento subjetivo para implicar a responsabilidade de reparar ou compensar um dano a outrem.

Foi realizado um estudo de caso com o fito de analisar os eventos danosos ocorridos no referido município de Mariana, assim como as ações civis públicas que foram ajuizadas e os institutos jurídicos inerentes. Centralizaram-se as reflexões na responsabilidade objetiva com base na teoria do risco integral conforme delimitação pautada nas tendências contemporâneas da responsabilidade civil.

Através do método de pesquisa dedutivo, aliado à pesquisa bibliográfica-documental, busca-se contribuir com a transformação da responsabilidade civil, considerando os ditames da Constituição Federal de 1988. Em consonância a isto, almeja-se verificar o papel do sistema jurídico na tutela dos interesses metaindividuais.

Buscou-se compreender questões fundamentais relacionadas às funções reparatórias e precaucional, evidenciando a atuação do Judiciário brasileiro, assim como dos órgãos ministeriais e fiscalizatórios. Ademais, investigou-se o alcance da proteção jurídica conferida aos interesses metaindividuais, assim como a relevância destes para os interesses da sociedade civil.

Verificou-se a viabilidade em ampliar os limites de interpretação do direito privado no sentido de reformulá-lo com fulcro nas tendências contemporâneas. Além disso, pesquisou-se a relação entre os danos ambientais ocorridos no município de Mariana, Minas Gerais, e as tendências mencionadas e, de que forma estas incidem na práxis jurídica, de modo a evitar a repetição dos danos já ocorridos, além de compreender de que forma podem ser dirimidos os danos já constatados. Assim, esta pesquisa levantou a hipótese de que a função preventiva do Direito por ser pouco utilizada, não colabora para abrandar os riscos ambientais já existentes, que podem se concretizar em danos.

A pesquisa é realizada com o objetivo de contribuir com a transformação da responsabilidade civil, considerando os ditames da Constituição Federal de 1988 e a necessidade de humanização das relações privadas. Em consonância a isto, almeja verificar o papel do sistema jurídico brasileiro na tutela dos interesses metaindividuais. Em suma, quer-se um Direito que atue de modo ativo, ainda que imparcialmente (no caso de medidas adotadas pelo Poder Judiciário), e que colabore com a construção de um Estado Social.

Com o fito de que o ciclo de tragédias se encerre é preciso remodelar o Direito, a despeito do novo rompimento de barragem, ocorrido desta vez no município de Brumadinho, também no estado de Minas Gerais, o qual será alvo de análise futura mais detalhada, uma vez que ocorreu recentemente. Assim, indaga-se: de que forma é possível proteger o meio ambiente no cenário atual, permeado de complexidades?

\section{ANÁliSE dA TEORIA do Risco INTEGRAL}

No decorrer da história humana, conforme asseverou Santos (2014, p. 23-24), os sistemas técnicos foram diminuindo e sendo unificados a nível mundial, seguindo o ritmo do capitalismo. 
Os ordenamentos jurídicos não ficaram alheios a este movimento unificador, sobretudo, porque o direito é grandemente construído em reação às alterações construídas pela sociedade.

O Código Civil contém previsão acerca da responsabilidade aquiliana, expressa no artigo 186, que exige, imprescindivelmente, dolo ou culpa para configurar um ato ilícito. A Lex Aquilia de Damno, de Roma Antiga, criou suporte para esta teoria de danos extracontratual - sobretudo em seu capítulo intitulado como damnum injuria datum, o qual, em suas passagens, efetivou para o dono de determinada coisa o direito à reparação mediante a prova da culpa do lesante (mais tarde, foi proporcionado também aos possuidores diretos, indiretos e determinados detentores). (LIMA, 1938, p.12).

Este autor também aduziu que o prejuízo leva à vítima a buscar proteção jurídica. Desse modo, a responsabilidade do agente pode ser fixada considerando também a justificativa de sua conduta, não bastando o fato lesivo ao direito alheio quando se tratar de responsabilidade extracontratual sob a ótica da culpa.

$\mathrm{O}$ autor referido distinguiu a culpa in abstracto da culpa in concreto. Para aquela, observa-se a capacidade delitual do lesante, assim como sua imputabilidade moral. Para a última, leva-se em consideração o estado de consciência do agente, colocando-se no lugar deste. Por isto que para a primeira classificação de culpa, abstrai-se as diversas circunstâncias internas daquele que praticou o delito.

Contrariamente a esta construção jurídica, o Código Civil, no parágrafo único do artigo 927, consubstancia exceção ao dever de indenizar outrora consubstanciada no caput. Neste caso, gera-se a obrigação reparatória quando o mal perpetrado o for em virtude de atividade que implique riscos para direitos alheios.

O artigo 927, alude expressamente à "atividade normalmente desenvolvida pelo autor do dano" que implique "por sua natureza, risco para os direitos de outrem". Em observância ao próprio decurso da história até que a responsabilidade privada alcançasse a supressão da análise da culpa, é possível aduzir que está relacionada à própria proteção das liberdades individuais, situação que foi se tornando mais complexa com o desenvolvimento das tecnologias.

Neste sentido, fala-se em direito de propriedade, de integridade física, de proteção ao direito de imagem e à moral, bem como o direito de autodeterminação dos homens, os quais são feixes jurídicos que figuram como relevantes e merecedores de cautela mais robusta. Por derradeiro, apoiando-se, inclusive, no princípio da razoabilidade, a norma contida no artigo 927 da codificação multicitada almeja proteger riscos elevados, atividades que por sua natureza manifestem alta possibilidade de danos, marcante, evidente, de forma limítrofe a uma situação de probabilidade.

O artigo 225, parágrafo terceiro, da Constituição Federal, por sua vez, estabeleceu que condutas e atividades que lesem o meio ambiente geram a obrigação de reparar os danos que foram perpetrados, além das sanções penais e administrativas atinentes. Assim, é primeiramente no âmbito constitucional que se cria um campo de proteção do meio ambiente, enquanto componente da ordem social. A despeito da relevância deste bem jurídico, há apenas o artigo 225 inserido no Capítulo VI da norma constitucional.

O caput deste dispositivo delimita o direito de todos ao meio ambiente ecologicamente equilibrado, que é um bem de uso comum do povo e essencial à sadia qualidade de vida. O Poder Público e a coletividade devem defendê-lo e preservá-lo para as presentes e futuras gerações. Ademais, a Lei ${ }^{\circ}$ 6.938, sancionada em 1981, recepcionada pelo ordenamento constitucional, 
O inverso da análise da culpa: leitura da teoria do risco a partir do rompimento de barragem em Mariana/MG

no artigo 14, parágrafo primeiro, dispôs sobre a responsabilidade objetiva para reparar e indenizar danos causados ao meio ambiente, assim como a terceiros, em virtude de atividades de determinado poluidor.

A tutela ambiental, da forma que está inserida na legislação, detém fundamentos éticofilosóficos. Alcançou o patamar atual com a influência do cristianismo, a qual ensejou a visão antropológica da ecologia na jurisprudência brasileira. Este ramo do saber foi desenvolvido pelo direito canônico excluindo a interação entre meio ambiente e ser humano. (DESTEFFENI, 2005, p. 22-27).

A ecologia, ou o estudo da casa, partindo de sua etimologia, que impulsiona o ser humano a preservar a natureza, pode ser compreendida em vertente mais complexa e estimular que seja preservada a integridade da biosfera a despeito de qualquer benefício antropocêntrico. Determinada espécie ou ecossistema podem ser compreendidos como entidades em si, que contemplam interesses individuais. Desta forma, consoante a ética proposta por Peter Singer, o valor da preservação daquilo que resta de espaços naturais. (LEÃO; MAIA, 2010, p. 110-111).

No esteio da Lei $n^{\circ}$ 6.938/81, que dispõe sobre a Política Nacional do Meio Ambiente, verifica-se o objetivo do ordenamento jurídico em preservar, aprimorar, bem como em recuperar, em última instância, a vida, mediante a manutenção da qualidade do meio ambiente (conforme se denota do artigo $2^{\circ}$ ). $\mathrm{O}$ artigo $4^{\circ}$ desta legislação expõe, especificamente, os propósitos da política nacional, consistentes em compatibilizar o desenvolvimento da economia e da sociedade, de forma sincrônica, com o aspecto qualitativo do meio ambiente, almejando um estado de equilíbrio (no esteio do inciso I).

Informa, ademais, que (consoante inciso VI) os recursos ambientais devem ser utilizados racionalmente para serem preservados e restaurados, estando disponíveis permanentemente. Rememora-se o artigo 225 da Constituição Federal, que determina a imperiosidade de perpetuar o meio ambiente harmonioso para as gerações presentes, além daquelas que estão por vir. Este artigo constitucional cria bases para a responsabilidade objetiva pautada em risco, no parágrafo terceiro, ao determinar que as condutas e atividades que lesem o meio ambiente geram, para os infratores, sanções penais, administrativas, além das demandas cíveis com o fito de reparar os danos consubstanciados.

Como mecanismo para efetivar a Política Nacional do Meio Ambiente prevê-se a responsabilidade independente de dolo ou culpa para o indivíduo que desestabilizar o equilíbrio antes existente no espaço ambiental. Degradá-lo provoca a responsabilidade abarcada pelo parágrafo primeiro do artigo 14. Restou estabelecido o dever de indenizar, assim como o de reparar, sendo suficiente a prova do dano e do nexo de causalidade.

O pensamento atinente à responsabilidade objetiva, com base na Teoria do Risco Integral, demanda a lição formulada por Lima (1938). Como se sabe, as invenções modernas geraram perigos e, por conseguinte, diversos acidentes, como também a impossibilidade em provar a culpa daquele que praticou o ato ilícito tornou-se crescente. $\mathrm{O}$ autor compreendeu que o Direito deveria se posicionar enquanto ciência que nasceu da vida e foi criada para discipliná-la, devendo, portanto, resguardar tais situações. (Ibid., p. 16).

Consoante as lições de deste autor, há defensores e críticos da teoria do risco. Acerca daqueles que têm posicionamento contrário, constatou duas vertentes argumentativas conforme os ensinamentos de Pierre Savatier: na primeira, afirmam que é possível configurar a obrigação de reparar sem que tenha havido culpa. Todavia, caracteriza-se como garantia, e não como responsabilidade. $\mathrm{O}$ douto jurista assevera que este argumento trata, tão somente, de uma querela acerca da definição do regime jurídico; de qualquer forma, aduz-se sobre um acordo em que há 
o dever de reparar o prejuízo. A segunda corrente nega a obrigação de reparar o dano sem culpa, a não ser que haja previsão legal ou contratual.

Observa-se, nesse ínterim, a importância em verificar a possibilidade de repristinar o meio ambiente ao status quo ante (ROSENVALD, 2017, p.103). A compensação deve ser pautada, sobretudo, em caráter complementar, conforme liames da reparação integral.

O artigo 225, parágrafo terceiro da Constituição Federal, informa que os sujeitos infratores podem condizer a pessoas físicas ou jurídicas. Neste sentido, a fim de ampliar o resguardo aos interesses ambientais, firmados no texto constitucional, os tribunais, no que tange aos direitos das relações de consumo, assim como aos ambientais, aplicam a desconsideração da personalidade jurídica com base na denominada Teoria Menor. Para danos cometidos em face de direitos consubstanciados e firmados pela Lei $\mathrm{n}^{\circ} 8.078 / 90$, aplica-se o artigo 28, parágrafo quinto, desta codificação. Para as lesões ambientais, aplica-se a Lei n ${ }^{0}$ 9.605/98, dispondo, especificamente, sobre crimes infrações administrativas, bem como cooperação internacional com o mote de preservar o meio ambiente.

A 22a Câmara Cível do Tribunal de Justiça do Rio Grande do Sul compreendeu neste sentido quando julgou o agravo de instrumento $\mathrm{n}^{\circ} 70063254916$ em procedimento de execução, sendo o recurso provido de plano. Aplicou o artigo $4^{\circ}$ da Lei $\mathrm{n}^{\circ} 9.605$, de 1998 , que menciona ser possível desconsiderar a personalidade da pessoa jurídica sempre que for identificada como obstáculo ao ressarcimento dos danos praticados em face do meio ambiente. Como pano de fundo, restam presentes os princípios do poluidor-pagador e da reparação integral. (KOHLER, 2012, p. 133).

Avulta-se a teoria do risco integral em concordância à jurisprudência hodierna do Superior Tribunal de Justiça. Em julgamento do Recurso Especial no 1.374.342/MG, com relatoria do Ministro Luis Felipe Salomão, evidenciou-se o posicionamento de que é esta a teoria aplicada aos casos que tragam ao crivo do órgão superior danos ambientais. Concluiu-se que conseqüências prejudiciais às pessoas, assim como ao meio ambiente geram a responsabilidade objetiva.

Nesta senda, a teoria lastreia três proposições: a primeira, inerente à teoria objetiva do "direito de danos", segundo assevera Guimarães (2004, p. 95), e que consiste em se concretizar como prescindível o exame da culpa; após, verifica-se ser irrelevante apurar a licitude da atividade que produziu o prejuízo ambiental, isto é, a regularidade da licença perante o órgão de ambiental competente não afasta a responsabilidade civil; e, a ausência de aplicação das causas excludentes de responsabilidade civil, afastando-se, portanto, o caso fortuito ou força maior. (MILARÉ, 2005, p. 834).

Além desta compreensão de Édis Milaré, o autor Marcos Destefenni aduz que a responsabilidade por dano ambiental é objetiva. Portanto, analisa-se o nexo de causalidade entre a conduta e a lesão perpetrada; em outras palavras, para se afastar a responsabilidade objetiva, devese afastar o nexo causal. (DESTEFFENI, 2005, p. 163).

Em sentido oposto, parte da doutrina brasileira admite a existência destas excludentes, posicionamento adotado Paulo Bessa Antunes, que entende pela ausência de base legal para afastar o caso fortuito e a força maior. Asseverou que a inadmissão das excludentes pela jurisprudência majoritária do Superior Tribunal de Justiça conota que foi internalizada, às decisões, "visão pessimista em relação ao futuro". Compreendeu que banir as causas supramencionadas corresponde a adotar perspectiva punitiva em relação ao causador do dano. (ANTUNES, 2016, p. 107).

No que tange à responsabilidade do Estado por conduta omissiva que tenha lesado o meio ambiente, constata-se que os tribunais vêm aplicando a teoria subjetiva. Este, esmiuçado em 
O inverso da análise da culpa: leitura da teoria do risco a partir do rompimento de barragem em Mariana/MG

União, Estados, Distrito Federal e Municípios, para ser condenado dependerá de ter sido configurado o elemento subjetivo em relação à omissão.

O Superior Tribunal de Justiça julgou o Recurso Especial $n^{\circ}$ 1.417.023/PR, interposto pelo Instituto Brasileiro do Meio Ambiente e dos Recursos Naturais Renováveis (IBAMA), compreendeu que foi caracterizada a omissão do órgão no que tange ao dever de fiscalização. $\mathrm{O}$ IBAMA, todavia, compreendeu que deveria ter incidido o artigo $3^{\circ}$, inciso IV, da Lei $\mathrm{n}^{\circ} 6.938 / 81$. No julgamento, consta que o órgão ambiental concorreu para a ocorrência da degradação ambiental de forma omissiva em relação ao dever de fiscalizar a área de reserva legal e preservação permanente, ferindo mandamento constitucional.

Em suma, passou-se a compreender que o risco tem de ser suportado por aquele que o originou. Louis Josserand asseverou que era significativo abandonar a visão subjetiva da responsabilidade para compreendê-la objetivamente, trocando a noção de culpa pelo entendimento do risco. (JOSSERAND, vol. LXXXVI. p. 556).

O sistema integral de compensação de danos permite que sejam transferidas, da vítima ao responsável, "todas as conseqüências suportadas", concretizando reparação, além de integral, "mais rápida, justa e incondicionada". (ROSENVALD, 2017, p. 129). Benjamim (1998, p. 123) assevera que, além de serem afastadas as excludentes de ilicitude, o evento ocorrido "no curso ou em razão de atividade potencialmente degradadora" cria, para o responsável, o dever de reparar os eventuais danos que foram causados.

\section{FUNÇÃO PREVENTIVA DA RESPONSABILIDADE CIVIL COM BASE NA SOCIEDADE DE RISCOS}

O risco, após o período de Revolução Industrial, no século XVIII, começou a ser estudado por sociólogos, economistas, filósofos, como também juristas. Para Maria Alice Costa Hofmeister não é possível fugir do risco, uma vez que diz respeito ao tempo futuro (HOFMEISTER, 2000, p. 37). E, logo, a diversos campos da sociedade, sendo, por isto, estudado por variados domínios do conhecimento.

Ter-se criado máquinas, técnicas de produção em larga escala industrial, criou dificuldade probatória ampla para as vítimas de acidente, sobretudo trabalhadores. Raymond Saleilles e Louis Josserand concluíram que o empreendedor - em virtude dos lucros e vantagens obtidos deveria suportar todos os encargos oriundos de sua atividade econômica (HENKES, 2009, op. 54).Por isto, engendraram a Teoria do Risco da Atividade.

O risco, consoante expôs Hofmeister, com apoio no pensamento de Raffaele di Giorgi, não se confunde com perigo, pois é imputado a uma decisão. Exemplificou que duas pessoas, numa mesma situação, podem estar expostas ao risco e ao perigo; respectivamente, para o que conduz um veículo temerariamente e para aquele que observou as normas de trânsito correspondentes às circunstâncias em que se encontre inserido. Desta forma, o perigo diz respeito a danos possíveis não relacionados com determinada escolha. (HOFMEISTER, 2000, p. 37-38).

Prosseguiu aduzindo que existe o risco que depende do comportamento individual (no esteio do exemplo do acidente de trânsito), da empresa e da coletividade, que ao ser modificado, pode afastar a previsibilidade do dano. O sujeito comporta-se como elemento central de quaisquer ações no mundo. (ROBALINHO, 2014, p. 54). De outro lado, há o risco maior, de modo que há a possibilidade de serem tomadas medidas, com mote preventivo, cabíveis evidentemente ao ente público. (Ibid, p. 43-44). 
Robalinho (2014), com viés do sociólogo alemão Ulrich Beck, aduz que o futuro está em patamar sublime em face do passado. Informa que a modernidade passa por processo de ruptura histórico, configurando-a como sociedade industrial de riscos; os bens criados nesta época são dominados pela produção de riscos. Asseverou que os estudos efetivados por Beck orientam a compreensão acerca da necessidade do ser humano de controlar a realidade "frente às inseguranças com as quais a sociedade diariamente se defronta", assim como em face da impossibilidade de se controlar amplamente as circunstâncias fáticas. Italo Calvino, conforme salientou Rosenvald, ratifica esta ideia, pontuando que os meios de controle e de conhecimento são renovados à medida em que se desenvolvem dificuldades à vivência humana. (ROBALINHO, 2014, p. 53$55)$.

A centralidade individual envolvida pela criação de riscos, remete ao indagamento realizado por Nelson Rosenvald: "qual mundo tomaremos a responsabilidade de deixar para os nossos filhos?". O estudioso prosseguiu aduzindo que não se trata apenas de questionamento com viés ambiental conforme conota-se precisamente da Constituição Federal, no artigo 225, em sua completude. Este posicionamento liga-se ao princípio da prevenção, elencado como cerne da responsabilidade civil contemporânea. (Ibid. p. 32).

É corriqueiro escutar ou proferir que "é melhor prevenir, do que remediar", isto é, reparar - função remota da responsabilidade civil que tem como superfície a prevenção lato sensu (ao inibir reflexamente o ofensor a causar prejuízos similares). Para Nelson Rosenvald, "na função reparatória, a indenização é acrescida a uma "prevenção de danos"; na função punitiva, a pena civil é acrescida a uma "prevenção de ilícitos"”, e, por fim, a função precaucional acresce-se da prevenção dos riscos. Em face das exigências econômicas e sociais, reparar os danos, mote da teoria do risco, deve se aliar à prevenção dos ilícitos, conforme o estatuto jurídico da pena civil. (Id. Ibid. p. 33-34)

Conforme assinalou Gordilho (2009, p. 61-62), estes danos podem ser ilimitados, globais, como também irreparáveis. Assim, implementar políticas públicas ambientais é um caminho para efetivar a função preventiva. Entretanto, como salienta Silva; Gordilho; Braz (2017, p. 873-874), há um déficit oriundo da ausência de instrumentos necessários no âmbito dos órgãos estatais, dificuldades político-administrativas, como também "interesses econômicos de grupos poderosos que acabam prevalecendo". É possível que a participação popular colabore para implementar as normas ambientais ao lado desta atuação estatal. (Ibid., p. 873-874). Gomes e Carvalho (2018, p. 15) reconhecem que é necessário o "comprometimento dos órgãos públicos na busca por uma educação ambiental realmente eficaz".

\subsection{Do princípio da precaução aos danos ambientais}

Adotado pela Conferência das Nações Unidas sobre Meio Ambiente e Desenvolvimento, ocorrida no Rio de Janeiro em 1992, o princípio da precaução possui as primeiras referências sedimentadas nos anos oitenta com o fito de proteger a camada de ozônio. (HAMMERSCHMIDT, 2002, p. 107).

Por esta razão, sinaliza as mudanças filosóficas e sociológicas que ocorreram neste final de século. (Ibid., p. 109). O item 15 deste instrumento informa que o princípio da precaução deve ser observado pelos Estados de maneira ampla conforme as suas capacidades internas. Havendo ameaça de danos sérios ou irreversíveis, não poderá ser alegada a ausência de absoluta certeza científica com o fito de postergar medidas tidas como eficazes, bem como aquelas que sejam economicamente viáveis a prevenir lesões ambientais. 
O inverso da análise da culpa: leitura da teoria do risco a partir do rompimento de barragem em Mariana/MG

No esteio das palavras de Hammerschmidt (2002), o princípio da precaução comporta-se como norma que estrutura o Estado de Direito Ambiental. Trata-se de um raciocínio pautado na ética da decisão que é necessária para coibir degradações ambientais em um contexto de incertezas. (Ibid. p, 109).

Neste sentido, foi interposto agravo regimental em suspensão de liminar e de sentença $\mathrm{n}^{\circ}$ 1.429/GO, pela Câmara Municipal de Novas Caldas, perante o Superior Tribunal de Justiça com o objetivo de suspender a decisão judicial que proibiu que fossem instalados novos empreendimentos imobiliários no município de Novas Caldas. Alegou-se que a decisão que inibe o município a permitir a instalação de novos empreendimentos fere a ordem e economia públicas.

Contudo, no voto do Ministro Ari Pargendler, consta que se configurava como imperioso ampliar a rede de esgotos ou, mesmo, construir uma nova rede para viabilizar as instalações. $\mathrm{Na}$ ementa, expôs-se que, nas matérias atinentes ao meio ambiente, aplica-se o princípio da precaução em virtude de se ter constatado a potencialidade em causar danos graves ao meio ambiente e à saúde da população.

É neste contexto que Hammerschmidt (2002) informa acerca dos dois pressupostos que lastreiam o princípio multicitado. Versam sobre a possibilidade de que as condutas praticadas pelos indivíduos provoquem danos coletivos associados, inclusive, a situações calamitosas. E, ainda, corresponde à desnecessidade de evidência científica (isto é, de que haja certeza) sobre o dano. Basta que seja temido, suspeitado. Trata-se de princípio que envolve dúvida, pois o risco não é delimitável. (Ibid, p. 109).

Boff (2004, p. 14-17), constatando que a Terra está doente, assevera que para compreender as relações ecológicas é necessário vislumbrar as interconexões com outros saberes, pois não há como ser conceituada em si mesma.

Prosseguiu aduzindo que a natureza não é um sistema mecânico plenamente controlável pelo ser humano, no escólio de Fendstadt (HAMMERSCHMIDT, 2002, p. 110). Por isto, os riscos devem ser percebidos em associação aos interesses sociais coletivos (como meio ambiente, saúde pública), que estão defrontes às pressões dos interesses econômicos - a exemplo da livre circulação de mercadoria, produção de riquezas e jogos de concorrência. (Ibid., p. 109).

Em suma, consoante aduziu Álvaro Luiz Valery Mirra, trata-se de princípio geral do Direito Ambiental e que integra o ordenamento jurídico brasileiro. Denota-se que impõe prudência e vigilância no que tange às condutas e às atividades que são potencialmente lesivas ao meio ambiente, não sendo possível firmar situação de tolerância para tais situações. Os juízes, por esta razão, podem decidir com base em probabilidades fundadas em riscos sérios para impedir, cessar ou mitigar danos ao meio ambiente. Devem abster-se da necessidade de certezas para apurar as lesividades indicadas nos casos concretos. (MIRRA, 2001, p.11).

Nesse sentido, Rosenvald (2017, p. 120) alegou que se tratam de riscos que no momento em que surgem comportam-se como representações de destruições. A consciência do risco não está centrada no presente. Está vislumbrada para o futuro. O passado não tem mais força dominante em relação ao tempo vigente. As condutas exercidas o são para evitar problemas ou crises "do amanhã", isto é, com o fito de ter atitudes de precaução em relação ao tempo que está por vir.

Desta forma, com o objetivo de "enfrentar riscos e ameaças iminentes, de forma a antecipar certa carga de segurança social, o direito se acautela lançando mão dos princípios da prevenção e da precaução". Nesse sentido, dilui-se o nexo de causalidade entre o evento com potencialidade lesiva e o dano de modo a antecipar a prevenção a um âmbito temporal que é anterior à possibilidade de que ocorra qualquer lesão. (Ibid., 120-121). 
A prevenção e a precaução foram erigidas como funções da responsabilidade civil por danos ambientais e baseiam o princípio do poluidor-pagador. Este orienta o ressarcimento do dano por quem dele houver sido beneficiado (ou a compensação, no caso dos danos morais), segundo Gomes (2016, p. 76). O poluidor tem o dever de arcar com as despesas oriundas da reparação, assim como da prevenção das atividades poluidoras.

Consequentemente, consoante asseverou Krell (1998, p. 35), a densidade de responsabilidade é maior para o agente economicamente mais forte; assim, leva-se em consideração a capacidade individual do agente poluidor. $\mathrm{O}$ autor sugere a possibilidade de a poluição do meio ambiente concretizar-se como hipótese de incidência para cobrança de impostos ou taxas do particular. (Ibid. 36-37).

O poluidor integra os custos ambientais e configura-se como primeiro pagador, seguindo os dizeres Annelise Steigleder. (STEIGLEDER, 2002, p. 265). Desse modo, estas funções são relevantes ao passo em que, constatou-se, conforme estudos elencados por José Rubens Morato Leite e Melissa Ely Melo, que há "déficit de execução no sistema de controle e comando público ambiental”. (LEITE, 2007, p. 209).

\title{
3. ANÁlise dOS FATOS DANOSOS OCORRIDOS EM MARIANA/MG
}

A mineração é uma atividade importante desenvolvida no estado de Minas Gerais, a qual, todavia, produz impactos negativos sobre o meio ambiente. "Desastre ambiental" foi à expressão sucinta que marcou o rompimento da barragem de Fundão em novembro no ano de 2015. Sua estrutura foi construída em 2007, próximo à cidade de Mariana, pela empresa denominada como Samarco Mineração S.A., junto às acionistas Vale S.A. e BHP Billiton Brasil Ltda. (ALVES; SILVA, 2016, p. 227).

Assim como as demais barragens de rejeitos de mineração (SOARES, 2010, p. 832) foi criada para armazenar resíduos sólidos e a água resultantes dos processos de beneficiamento do minério, uma vez que os rejeitos contêm elevado grau de toxicidade - os quais são prejudiciais ao meio ambiente e à saúde humana ${ }^{1}$. Conforme passagens da Normas Reguladoras de Mineração (NRM) - constantes na Portaria $\mathrm{n}^{\circ} 12$, publicada no Diário Oficial da União (DOU) em 29 de janeiro de 2002 e na Portaria $n^{\circ} 237$, publicada no DOU de 19 de outubro de 2001 -, o processo de tratamento ou beneficiamento de minérios tem o objetivo de prepará-los granulometricamente, conservá-los ou purificá-los, empregando-se métodos químicos ou físicos, de modo que a constituição química dos minerais não deve ser alterada.

Lindolfo Soares asseverou que as "atividades relacionadas à produção mineral geram um volume significativo de massa do minério que é rejeitada nos processos de lavra e beneficiamento".

\begin{abstract}
A crescente demanda mundial por bens minerais, aliada ao desenvolvimento econômico e tecnológico, condiciona, de forma sustentável e economicamente viável, o aproveitamento de minérios de baixo teor ou mesmo aqueles de difícil beneficiamento. Esta situação conduz a um aumento expressivo na quantidade de rejeitos produzidos, superando, em muito, aquela advinda dos próprios minérios. (SOARES, 2010, p. 832).
\end{abstract}

Dispondo acerca do beneficiamento, em sua seção $\mathrm{n}^{\circ} 18$, a NRM determina que o projeto correspondente deve "otimizar o processo para obter o máximo aproveitamento do minério e dos

\footnotetext{
1 Documentos sobre o desastre do Rio Doce. Disponível em: http://www.brasil.gov.br/meio-ambiente/2015/12/confira-documentos-sobre-o-desastre-do-rio doce/acao_inicial_agu_es_mg_samarco.pdf. Acesso em: 20 nov. 2017.
} 
O inverso da análise da culpa: leitura da teoria do risco a partir do rompimento de barragem em Mariana/MG

insumos, observadas as condições de economicidade e de mercado". Ademais, deve "desenvolver a atividade com a observância dos aspectos de segurança, saúde ocupacional e proteção ao meio ambiente".

Acerca da proteção ao meio ambiente, à saúde, bem como à integridade física do trabalhador, a portaria determina que "devem ser adotadas as medidas de proteção coletiva e, quando não for possível tecnicamente, fornecer Equipamentos de Proteção Individual - EPI" conforme a legislação vigente à época dos fatos, em virtude "de agentes químicos, físicos e biológicos" que possam afetar tais direitos regulados pelo ordenamento jurídico.

O rompimento da barragem de Fundão, no complexo minerário de Germano, próximo ao subdistrito de Bento Rodrigues (localizado no município de Mariana em Minas Gerais), desencadeou o deslocamento dos rejeitos para outra barragem componente do complexo, denominada Santarém. A lama criada atingiu a Bacia Hidrográfica Rio Doce e, por conseguinte, 41 municípios da unidade federativa supracitada, bem como do Estado do Espírito Santo.

Conforme relatório elaborado pelo Ministério do Trabalho e Previdência Social, após fiscalização que durou cinco meses, constatou-se que treze trabalhadores, contratados pela Samarco Mineração S.A., falecerem em virtude do rompimento da barragem. Residentes do município de Bento Rodrigues também foram a óbito; ao final, conforme o documento, dezoito pessoas faleceram.

\subsection{Da ação civil pública ajuizada pelo Ministério Público Federal}

Onze dias após os fatos danosos, em novembro de 2015, foram celebrados dois termos de ajustamento de conduta. Um deles, o Termo de Compromisso Socioambiental (TCSA), preliminar e emergencial - visto que as externalidade ambientais eram desconhecidas em sua integralidade e havia necessidade de minimizar os danos - foi firmado entre o MPF, o MPT, o Ministério Público do Estado do Espírito Santo e a empresa proprietária.

O Ministério Público Federal e as empresas Samarco Mineração S.A, Vale S.A. e BHP Billiton Brasil Ltda. celebraram acordo preliminar que foi homologado em parte pela $12^{\mathrm{a}}$ Vara da Justiça Federal de Minas Gerais. As empresas comprometeram-se a garantir o cumprimento das obrigações firmadas para viabilizar os Programas de Reparação Socioambiental e Socioeconômica, no valor, portanto, R 2,2 bilhões. Em caso de descumprimento, ressaltou-se a possibilidade de execução das garantias, compostas em aplicações financeiras, seguro-garantia e bens livres de quaisquer ônus.

Foi concretizada a "Força Tarefa Rio Doce" com o mote de reparar os danos sociais, ambientais e econômicos provocados pelo rompimento da barragem de Fundão. Para tanto, o Ministério Público Federal, por meio da Procuradoria da República nos Estados de Minas Gerais e Espírito Santo, ingressou com ação civil pública em face das empresas Samarco Mineração S.A, Vale S/A e BHP Billiton Brasil Ltda. (estas duas últimas configurando-se enquanto sócias controladoras), e, também contra a União, os Estados de Minas Gerais e do Espírito Santo.

Enquanto causadores diretos do dano ambiental, foi elencada a empresa mineradora, Samarco S.A, operadora da Barragem de Fundão. E, a Vale S.A., por despejar rejeitos da atividade desenvolvida na Mina de Alegria. Indiretamente, em virtude de desconsideração da personalidade jurídica, listou-se Vale S.A. e BHP Billiton Ltda., visto que eram sócias controladoras da Samarco. A desconsideração da empresa operadora da barragem foi tida como plausível para alcançar os patrimônios das sócias controladoras, com base no artigo $4^{\circ}$, da Lei $\mathrm{n}^{\circ}$ 9.605/98. 
Compreendeu-se que as falhas não foram apenas dos particulares. Por esta razão, os Estados de Minas Gerais e do Espírito Santo, assim como a União, foram suscitados como responsáveis indiretos pelas condutas omissivas. Verificou-se a "ausência de efetivo exercício do poder de polícia" e a "emissão da licença ambiental que autorizou o exercício da operação da barragem" (fl. 110).

Em soma, os entes públicos com competência ambiental (IBAMA, DNPM, SEMAD, IEF, IGAM e FEAM) ${ }^{2}$. Para estes, firmam-se dois tipos de responsabilidade: retrospectiva - consistente em evitar a ocorrência de danos ambientais - e, a prospectiva, uma vez que ocorrido dano, devem ser adotadas todas as medidas que mitiguem, recuperem e compensem o dano ambiental.

Salientou-se o direito fundamental ao meio ambiente equilibrado com base no artigo 225 da Constituição Federal (fl. 110). Ademais, evidenciou-se o princípio da indisponibilidade do interesse público ambiental, bem como o princípio do poluidor-pagador. Ainda, os princípios da prevenção e da precaução em conjunto ao princípio da reparação integral em razão de degradação provocada em face do meio ambiente. Ressaltou-se a existência de dano moral coletivo, visto que "valores imateriais da coletividade foram frontalmente atingidos" (fl. 134).

Propôs-se indenização com fito pedagógico, assim como em virtude do tempo decorrido entre o dano e a recuperação ou mesmo a compensação ambiental - configurando-se em lucro cessante. Compreendeu-se, ademais, que a responsabilidade civil configurou-se como objetiva, solidária e integral entre os causadores dos danos socioambientais e socioeconômicos.

Formulou-se pretensão jurídica acerca da proteção da ictiofauna da bacia hidrográfica do rio doce, bem como da região marinha impactada e dos consumidores de pescado. Entendeu-se pela proibição da pesca e também por medidas de vigilância sanitária visto que foram verificados indícios de contaminação da ictiofauna e da proibição da pesca.

A análise da "fração total na água (incluindo MPS) indicou um significativo aumento das concentrações de Alumínio ( $\mathrm{Al})$, Ferro (Fe), Manganês $(\mathrm{Mn})$ e Cromo $(\mathrm{Cr})$, sendo que o aumento chegou a vinte vezes para Ferro e cerca de seis vezes para Alumínio" (fl. 192). Esta situação fere o direito à saúde - direito fundamental de todos os cidadãos com fulcro no artigo 196 da Constituição Federal de 1988.

Propôs-se medidas de vigilância sanitária a serem implementadas pelo Sistema Único de Saúde (SUS), na forma prevista na Lei 8.080/90. A Política Nacional do Saneamento Básico também foi ferida consoante dispositivos da Lei n. 11.445/2007.

Vislumbrando a relevância do Código Florestal, a Lei n. 12.651/2012, foi pedida a condenação dos réus a "recompor as nascentes que sofreram danos em razão do rompimento da barragem de rejeitos de Fundão, e a efetuarem, como medida compensatória, a recomposição de outras nascentes ao longo da Bacia Hidrográfica do Rio Doce” (fl. 204). A Lei n. 11.428/2006 dispõe sobre a proteção da vegetação nativa da Mata Atlântica (tida como patrimônio nacional), que também foi afetada, "devendo a área total ser indicada no plano de recuperação ambiental, de forma proporcional ao dano causado" (fl. 206).

\footnotetext{
2 Respectivamente, Instituto Brasileiro do Meio Ambiente e dos Recursos Naturais Renováveis, Departamento Nacional de Produção Mineral, Secretaria de Estado de Meio Ambiente e Desenvolvimento Sustentável do Estado de Minas Gerais, Instituto Estadual de Florestas, Instituto Mineiro de Gestão das Águas, Fundação Estadual do Meio Ambiente.
} 
O inverso da análise da culpa: leitura da teoria do risco a partir do rompimento de barragem em Mariana/MG

\subsection{Do precedente judicial ocorrido na região}

Com o mote de demonstrar a atuação dos tribunais em casos similares ao ocorrido no município de Mariana, em Minas Gerais, efetiva-se comentário à jurisprudência do Superior Tribunal de Justiça por meio de julgado do Recurso Especial n ${ }^{\circ} 1.374 .342$. Trata-se de demanda individual proposta em face de Mineração Rio Pomba Cataguases, operadora de mineração de bauxita, para reparar por danos materiais e extrapatrimoniais.

Aludiu-se que em janeiro de 2007, em Miraí (cidade localizada no estado de Minas Gerais), ocorreu vazamento de resíduos tóxicos, com lama contendo bauxita, o que foi equivalente a bilhões de litros em virtude do rompimento da barragem. Os postulantes, moradores às margens do Rio Muriaé, sofreram danos em suas residências em virtude dos desdobramentos do evento danoso.

O voto do Ministro Luis Felipe Salomão evidenciou que a contenção dos rejeitos sólidos provenientes da atividade de mineração de bauxita era de responsabilidade da Mineração Rio Pomba Cataguases. E, que o evento danoso, consistente no rompimento da barragem de rejeitos, atingiu moradores das cidades de Miraí e de Muriaé.

A mineradora, que interpôs o recurso especial, alegou que a parte autora não demonstrou a existência de nexo causal entre o rompimento da barragem e os supostos danos. Aduziu que o município de Muriaé, no qual residia a postulante, foi atingido por muitas enchentes no mês de janeiro de 2007 - período em que ocorreu o rompimento da barragem operada pela empresa acima referida.

O entendimento da jurisdição de $1^{\circ}$ e $2^{\circ}$ graus, todavia, foi no sentido de que o nexo causal foi concretizado uma vez que armazenava resíduos oriundos da atividade mineradora e o vazamento dos rejeitos que inundaram cidades próximas. Demonstraram, desta forma, o liame entre a conduta e o dano perpetrado em face da população das cidades de Miraí e Muriaé.

Em primeiro grau, o magistrado afirmou que se trata de atividade tipicamente de risco, uma vez que existiam, em depósito, milhões de litros de rejeitos, que poderiam gerar prejuízo a outras pessoas - o que foi concretizado. Destacou que a operadora celebrou Termo de Ajustamento de Conduta com os Ministérios Públicos Federal e Estadual, no qual reconheceu a culpa do evento (que, conforme o exposto, sequer tem sua análise exigida), além de ter se comprometido a reparar todos os prejuízos morais ou materiais oriundos do vazamento de rejeitos tóxicos.

O magistrado de piso frisou que o laudo realizado pelo órgão ministerial do estado de Minas Gerais concluiu que a vida útil da barragem em questão finalizava em dezembro de 2005 . E, o evento danoso ocorreu dois anos após.

Elencou o artigo 334, inciso I, do Código de Processo Civil de 1973, o qual determina que não dependem de prova os fatos que sejam notórios. Isto é, o rompimento da barragem, por si só, ocasionou o transbordamento das águas do rio Muriaé. Ademais, evidenciou que a cor da água do rio foi alterada por ocasião da lama que o atingiu e que direcionou-se às ruas das cidades; e que a lama assoreou o leito do rio, de modo que toda chuva ocorrida posteriormente ao rompimento iria inundar as casas dos postulantes.

No acórdão recorrido, ressaltou-se que o nexo de causalidade decorre de fato público e notório, sendo divulgado de forma ampla pela mídia nacional e estrangeira. A ausência de aplicação de excludentes de responsabilidade afasta análise acerca do volume das chuvas, assim como da vazão do rio. 
No voto em questão, evidenciou-se o entendimento do Superior Tribunal de Justiça acerca do regime de responsabilidade civil a ser incidido no caso concreto. Entendeu-se pela aplicação da teoria do risco integral, a qual demanda análise objetiva em virtude da previsão constitucional constante do artigo 225, parágrafo terceiro, como também da previsão legal encontrada na Lei $\mathrm{n}^{\mathrm{o}}$ 6.938/81 (que dispõe sobre a Política Nacional do Meio Ambiente), no artigo 14, parágrafo primeiro.

Compreendeu-se que o explorador de atividade econômica enquadra-se como garantidor da preservação ambiental. Assim, os danos ligados às atividades de risco, a estas se vinculam, não sendo possível alegar excludentes de responsabilidade, como culpa exclusiva de terceiro e ocorrência de situação de força maior.

A mineradora alegou que a residência dos autores da demanda foi fortemente afetada em razão de chuvas pretéritas ocorridas, ainda, no mês de janeiro daquele ano de 2007. Em primeiro grau, nesta senda, sentenciou-se que a moradora teve de ser desalojada de seu imóvel residencial, ocasionando-lhe prejuízos imateriais. O tribunal a quo prosseguiu afirmando a existência de danos morais, salientando que a parte autora não voltou a residir na moradia atingida. Neste ínterim, não houve discussão sobre o valor a ser arbitrado a título de danos extrapatrimoniais.

Já no voto do Ministro Luis Felipe Salomão, foi trazido o artigo $4^{\circ}$, inciso VII, da Lei ${ }^{\circ}$ 6.938/81. É objetivo da Política Nacional do Meio Ambiente a reparação de todos os danos causados. Todavia, o ato ilícito para ensejar dano moral tem de atingir a dignidade da pessoa. Optouse por reafirmar as decisões anteriores proferidas neste caso as quais compreenderam que se concretizou, em desfavor das vítimas, angústias, preocupações, inquietações, além da normalidade.

Acerca do montante indenizatório que foi fixado, entendeu-se que o foi de forma razoável, sendo mantido no valor de dez mil reais. Ao recurso interposto, foi negado provimento.

Importante aduzir, que, acerca dos danos morais, doutrina e jurisprudência majoritárias vêm compreendendo pela implicação de responsabilidade mesmo quando forem coletivos (ou considerados como de massa, no esteio das lições de Geneviève Viney). (VINEY, 2008).

Considerando-se que se trata dano ambiental coletivo, importante destacar o rito processual pertinente. Edilson Vitorelli trabalhou com o aspecto que diz respeito à nova tipologia dos litígios coletivos e ofertou proposta para um conceito sociologicamente orientado dos direitos transindividuais. Assim, afirmou que as discussões relativas à titularidade de direitos de grupos, transindividuais, metaindividuais (asseverando que o mais significativo não é a denominação) foram cessadas, mesmo que tidas como relevantes. Em seu lugar, inseriu-se uma abordagem pragmática com o fito de garantir a tutela destes direitos a despeito de seu conceito não possuir delimitação exata. (VITORELLI, 2016, p. 35).

Edilson Vitorelli aduziu que se aceitou, doutrinariamente, que os direitos transindividuais são de todos, sejam grupos, seja a sociedade. A tautologia da tutela coletiva no Brasil informa que são de todos e, ao mesmo tempo, de ninguém.

\section{Conclusão}

Há casos além de Mariana, além de Miraí e de Muriaé. A mídia, com seu potencial informativo, noticia constantemente situações em que a qualidade ambiental está prejudicada. Estes casos ilustram o quanto a natureza permeia a vida do ser humano e a fragilidade que o meio ecológico carrega consigo. 
O inverso da análise da culpa: leitura da teoria do risco a partir do rompimento de barragem em Mariana/MG

O ordenamento jurídico tem de se posicionar em face desta realidade. Há uma busca, precípua, em proteger o lícito e, para que assim ocorra eficazmente, tem de se reprimir os ilícitos, corrigindo suas consequiências. Existente a ilicitude, ou, em outras palavras, uma situação de contrariedade entre conduta e norma jurídica, pode-se determinar deveres positivos ou negativos para o lesante.

No Direito Ambiental, impera a responsabilidade civil objetiva pautada no risco integral - em que não há análise de culpa, uma vez que havia dificuldade em prová-la em virtude da complexidade da vida moderna, que trouxe, crescentemente, uma multiplicidade de fatos catastróficos. Por isto, aquele que danifica o meio ambiente possui o dever jurídico de repará-lo integralmente com base em princípios de justiça e de equidade.

Ademais, é possível constatar, nos casos concretos, o regime jurídico de solidariedade entre os causadores dos danos - tenham atuado direta ou indiretamente. No caso de Mariana, a Samarco Mineração S.A., a Vale S.A. e a BHP Billiton Ltda., foram elencadas como causadoras do dano para responder de forma compartilhada. O Estado, por sua vez, conforme os tribunais admitem, pode responder em virtude das suas condutas omissivas - quando deixou de preservar e resguardar o direito fundamental ao meio ambiente estabelecido pela Constituição.

Numa sociedade comumente tida como de risco, é imprescindível que seja desestimulada qualquer atividade capaz de gerar efeitos prejudiciais, seja a terceiros, como, por exemplo, à população do município de Mariana, seja ao próprio meio ambiente. Assim, jurisprudência tem aplicado a Teoria do Risco Integral, na qual não se admite a incidência de excludentes da responsabilidade civil, como caso fortuito, força maior e fato de terceiro.

Os danos verificados em Mariana, em virtude do rompimento de barragem, e em sentido similar, nos municípios de Miraí e Muriaé, correspondem a lesões morais, bem como patrimoniais. Assim, é possível concluir que, conforme os casos analisados, trata-se de bem jurídico correspondente a direito fundamental. Logo, certo é que podem ser constatados danos morais a nível coletivo uma vez que se trata de interesse coletivo.

A Lei da Política Nacional do Meio Ambiente, ao definir o dano ambiental como modificação adversa de suas características, deu azo à instituição da Lei n ${ }^{\circ} 12.334 / 2010$, que, por sua vez, estabelece a Política Nacional de Segurança, criando o Sistema Nacional de Informações sobre Segurança de Barragens. Nos casos elencados, constatou-se que houve degradação da qualidade do meio ambiente (conforme artigo $3^{\circ}$, inciso III, e alíneas, da Lei $n^{\circ} 6.938 / 81$ ) em virtude de se ter prejudicado a saúde, a segurança e bem estar das populações afetadas pelos vazamentos, assim como criou condições desfavoráveis para o desenvolvimento de atividades sócio-econômicas.

Estas peculiaridades concretizam, conforme a norma, poluição em face do meio ambiente, apesar da visão com teor antropocêntrico. As alíneas "c", "d" e "e" conferem visão ecológica mais consciente ao que se entende legalmente por poluição ambiental, em virtude de se ter afetado desfavoravelmente a biota, condições estéticas ou sanitárias do meio ambiente, e, também, por ter sido lançadas matérias em desacordo com padrões ambientais.

Como foi visto, a demanda mundial por minerais é crescente e os minérios utilizados são de baixo teor ou de difícil beneficiamento, produzem, por conseguinte, uma grande quantidade de rejeitos. A complexidade da vida moderna reside na engenhosidade daquilo que vem sendo produzido pelo ser humano.

O valor da preservação daquilo que existe dos espaços naturais é incomparável ao valor econômico que é obtido até que haja a destruição, pois se trata de bem jurídico fundamental. As 
situações que envolvem ameaça de danos sérios ou irreversíveis exigem medidas eficazes - que não podem ser postergadas.

A fiscalização eficiente é um começo para que o ciclo de danos encerre, porquanto o princípio da precaução é o centro do Direito Ambiental. Dotar os órgãos de infraestruturas mais adequadas, engendrar um processo fiscalizatório mais consistente e coerente, inclusive com profissionais de diversas áreas, conscientes e preparados para desenvolver tais atividades é um meio de aprimorar o Estado Social. É viável remodelá-lo também fornecendo para a população espaço para colaborar com a construção do próprio ambiente em que se vive.

O que se busca é impedir que daqui um determinado período de tempo ocorra um novo rompimento de barragem como ocorreu em Brumadinho, Minas Gerais. Assim, encarar que existem danos que podem ser acentuados, ou mesmo desastrosos, e que o risco de que ocorram é incerto (porém, muitas vezes provável) é um prelúdio para que as normas sejam criadas e cumpridas com o fito de evitar que danos ambientais concretizem-se.

\section{REFERÊNCIAS}

ALVES, Leila Cristina do Nascimento; SILVA, Romeu Faria Thomé da. As respostas jurídicas do estado de Minas Gerais aos acidentes com barragens de rejeitos da mineração. Direito e Sustentabilidade IV. Santa Catarina: Conpedi, 2016.

ANTUNES, Paulo Bessa. Da existência da exclusão de responsabilidade na responsabilidade por danos ao meio ambiente no Direito Brasileiro. Revista Eletrônica de Direito Público. v.3. n.2. 2016.

BENJAMIN, Antonio Herman V. Responsabilidade civil pelo dano ambiental. Revista de Direito Ambiental. v. 9/5. 1998.

BOFF, Leonardo. Ecologia: grito da Terra, grito dos pobres. Rio de Janeiro: Sextante, 2004.

DESTEFFENI, Marcos. A responsabilidade civil ambiental e as formas de reparação do dano ambiental: aspectos teóricos e práticos. Campinas: Bookseller, 2005.

GOMES, Orlando. Responsabilidade civil. São Paulo: Ed. Forense, 2016.

GOMES, M. F.; CARVALHO, V. O. Educação ambiental e sua normatividade simbólica. Revista Jurídica da FA7, Fortaleza, v. 15, n. 1, p. 25, 2018.

GORDILHO, Heron José de Santana. Direito ambiental pós-moderno. Curitiba: Juruá, 2009.

HAMMERSCHMIDT, Denise. O risco na sociedade contemporânea e o princípio da precaução no direito ambiental. Revista Sequência, n. 95. 2002.

HENKES, Silviania L. A responsabilidade civil no direito ambiental brasileiro. Revista de Direito Sanitário, v. 10. n.1. São Paulo: 2009.

HOFMEISTER, Maria Alice Costa. O dano pessoal na sociedade de risco. Tese (Doutorado em Direito) - Faculdade de Direito, Universidade Federal de Santa Catarina. Florianópolis: 2000.

JOSSERAND, Louis. A evolução da responsabilidade civil. Revista Forense, Rio de Janeiro. vol. LXXXVI.

KRELL, Andreas Joachim. Concretização do dano ambiental: algumas objeções à teoria do risco integral. Revista de Informação Legislativa, vol. 39, Brasília, 1998. 
O inverso da análise da culpa: leitura da teoria do risco a partir do rompimento de barragem em Mariana/MG

LEÃO, Igor Zanoni Constant Carneiro; MAIA, Denise Maria. O valor do meio ambiente segundo Peter Singer. Economia \& Tecnologia. Ano 06. vol. 23. 2010.

LEITE, J. R. M; MELO, M. E.. As funções preventivas e precaucionais da responsabilidade civil por danos ambientais. Sequência: Revista do Curso de Pós-Graduação em Direito da UFSC. Vol. 28. n. 55. 2007.

LIMA, Alvino. Culpa e risco. São Paulo: Revista dos Tribunais, 1938.

MILARÉ, Édis. Direito do ambiente: doutrina, prática, jurisprudência, glossário. São Paulo, SP: Revista dos Tribunais, 2005.

MIRRA, Álvaro Luiz Valery. Direito Ambiental: o princípio da preucação e sua aplicação judicial. Revista de Direito Ambiental. n. 21. 2001.

ROBALINHO, Marcelo. Para além dos riscos: uma análise do livro Sociedade de risco. Revista Eletrônica de Comunicação, Informação e Inovação em Saúde. Instituto de Comunicação e Informação Científica e Tecnologia em Saúde da Fiocruz. 2014.

ROSENVALD, Nelson. As funções da Responsabilidade Civil. A Reparação e Pena Civil. São Paulo: Saraiva, 2017.

SANTOS, Milton. Técnica espaço tempo. Globalização e meio técnico-científico informacional. São Paulo: Edusp, 2014.

SOARES, Lindolfo et al. Barragem de rejeitos. In: Tratamento de minérios. 5. ed. Rio de Janeiro: CETEM/MCT, 2010.

STEIGLEDER, Annelise. Áreas Contaminadas e a obrigação do poluidor de custear um diagnóstico para dimensionar o dano ambiental. Revista de Direito Ambiental. v. 7. n. 25. 2002.

STEIGLEDER, Annelise Monteiro; MILARÉ, Édis; MACHADO, Paulo Affonso Leme (Orgs.). Doutrinas essenciais de direito ambiental: responsabilidade em matéria ambiental. São Paulo, Revista dos Tribunais, 2011.

SILVA, Tagore Trajano de Almeida; GORDILHO, Heron José de Santana; BRAZ, Laura Cecília Fagundes dos Santos. A participação popular na implementação das políticas públicas ambientais. Revista de Estudos e Pesquisas Avançadas do Terceiro Setor. v. 4. 2017.

VINEY, Geneviève. As tendências atuais do direito da responsabilidade civil. TEPEDINO, Gustavo (org.). In: Direito Civil Contemporâneo: novos problemas à luz da legalidade constitucional. São Paulo: Atlas, 2008.

VITORELLI, Edilson. O devido processo legal coletivo. Dos direitos aos litígios coletivos. São Paulo, Revista dos Tribunais, 2016.

Recebido em: 27 fev. 2019. Aceito em: 24 jul. 2019. 